\title{
EFICÁCIA DO FLUMIOXAZIN APLICADO NA DESSECAÇÃO PRÉ-COLHEITA DA SOJA E EFEITO RESIDUAL NO CONTROLE DE PLANTAS DANINHAS NO MILHO SAFRINHA
}

\author{
Fernando Tadeu de Carvalho ${ }^{1}$
}

${ }^{1}$ Prof. Dr. do Departamento de Biologia e Zootecnia, Universidade Estadual Paulista (UNESP), Faculdade de Engenharia, Câmpus de Ilha Solteira, SP. Email: ftadeu @ bio.feis.unesp.br

RESUMO: O objetivo do trabalho foi avaliar a eficácia do herbicida flumioxazin aplicado na dessecação pré-colheita da cultura da soja e o efeito residual no controle de plantas daninhas e na seletividade para a cultura do milho safrinha. O experimento foi desenvolvido de dezembro/2012 a setembro/2013, em Selvíria, MS. A semeadura da soja foi realizada de forma convencional e o milho foi semeado no sistema de plantio direto sobre a palhada da soja. Observou-se que o tratamento flumioxazin $\left(100,120\right.$ e 150 g p.c. ha $\left.{ }^{-1}\right)$ isolado foi eficiente na dessecação pré-colheita e seletivo na produtividade e germinação da cultura da soja cultivar ST 660, foi eficiente no controle residual de Alternanthera tenella, Ipomoea nil, Commelina benglalensis e Panicum maximum, e foi seletivo para a cultura subsequente de milho cultivar AG 8088 Pro. Os tratamentos flumioxazin + glyphosate (100, 120 e $150 \mathrm{~g}$ $+1,5 \mathrm{~L}$ p.c.ha $\left.{ }^{-1}\right)$, flumioxazin + paraquat $\left(120 \mathrm{~g}+2,0 \mathrm{~L}\right.$ p.c. $\left.\mathrm{ha}^{-1}\right)$ e flumioxazin + atrazin $\left(100 \mathrm{~g}\right.$ e $120 \mathrm{~g}+2,5 \mathrm{~L}$ p.c. ha $\left.^{-1}\right)$ também foram eficientes na dessecação pré-colheita e seletivos na produtividade e germinação da soja e foram eficientes no controle residual das plantas daninhas e seletivos para a cultura subsequente de milho.

Palavras-chave: Glycine max. Zea mays. Herbicida. Dessecantes.

\section{EFFICACY OF FLUMIOXAZIN APPLIED IN THE PREHARVEST DESICCATION OF SOYBEAN AND RESIDUAL EFFECT ON WEED CONTROL IN THE WINTER MAIZE}

\begin{abstract}
The objective of the work was to evaluate the efficacy of flumioxazin herbicide applied in desiccation pre-harvest of soybean and residual effect on weed control and selectivity for growing winter maize. The trial was conducted from December/2012 until September/2013 in Selvíria, MS, Brazil. The soybean planting was performed in the conventional manner and the corn was sown in no-tillage on soybean straw. It was observed that the treatment flumioxazin $\left(100,120\right.$ and $\left.150 \mathrm{~g} \mathrm{p.c.} \mathrm{ha}^{-1}\right)$ isolated, was effective in the drying pre-harvest and was selective in the productivity and germination of the soybean cultivar ST 660; was effective in residual controlling of Alternathera tenella, Ipomoea nil, Commelina benglalensis and Panicum maximum, and was selective for the subsequent maize crop cultivar AG 8088 Pro. The treatments glyphosate + flumioxazin (100, 120 and $150 \mathrm{~g}+1.5 \mathrm{~L}$ p.c. $\left.\mathrm{ha}^{-1}\right)$, flumioxazin + paraquat $\left(120 \mathrm{~g}+2.0 \mathrm{~L}\right.$ p.c. $\left.\mathrm{ha}^{-1}\right)$ and flumioxazin + atrazin $\left(100 \mathrm{~g}+120 \mathrm{~g}\right.$ and $2.5 \mathrm{~L}$ p.c. $\left.\mathrm{ha}^{-1}\right)$ were also effective in the desiccation pre-harvest
\end{abstract}


and selectives in productivity and germination soybean and were efficient in the residual control of the weeds and selectives for the subsequent maize crop.

Key words: Glycine max. Zea mays. Herbicide. Desiccants.

\section{INTRODUÇÃO}

As culturas de soja e milho estão entre as mais importantes do Brasil, sendo as maiores áreas agrícolas plantadas, com 33,9 milhões de hectares de soja e 17,5 milhões de hectares de milho colhidos neste ano, sendo os valores de produtividade atingidos ultimamente bastante competitivos com o resto do mundo, 3,3 ton.ha ${ }^{-1}$ para a soja e 5,4 ton.ha ${ }^{-1}$ para o milho (IBGE, 2017).

As técnicas de cultivo utilizadas na agricultura são muito modernas em áreas que possuem alta tecnologia e, entre elas, destaca-se a colheita mecanizada, o que viabiliza a operação, principalmente, nas extensas áreas de plantio da cultura. Para a colheita mecanizada a utilização de herbicidas dessecantes aplicados na pré-colheita é muito interessante para facilitar a operação, além disso, os dessecantes uniformizam a umidade dos grãos e a maturação e controlam as plantas daninhas que ocorrem no final do ciclo da cultura que poderiam prejudicar a operação de colheita e qualidade dos grãos colhidos.

Segundo dados da EMBRAPA (2003) a colheita das culturas na presença de folhas e ramos verdes provoca uma contaminação dos produtos colhidos, aumentando a umidade e prejudicando a qualidade do produto. Almeida et al. (1991) citam que a dessecação facilita o trabalho das máquinas colhedoras e permite a antecipação da colheita, com redução dos prejuízos decorrentes principalmente por fungos que incidam sobre a cultura no final do ciclo. Resultados positivos da dessecação também foram observados por Durigan (1980), Lacerda et al. (2003), Pelúzio et al. (2008), Kappes et al. (2009), Daltro et al. (2010).

Atualmente os produtos registrados para a dessecação da cultura da soja, segundo Rodrigues e Almeida (2011), são os herbicidas amônio-glufosinato, o paraquat, o diquat e o flumioxazin. O flumioxazin possui como mecanismo de ação a inibição da enzima protoporfirinogênio oxidase, que atua na oxidação de protoporfirinogênio a protoporfirina IX, precursores da clorofila. Com a inibição da enzima, ocorre o acúmulo de protoporfirinogênio, que se difunde para fora do centro reativo, em que acontece uma oxidação não enzimática do mesmo. Ocorre, então, a interação entre o oxigênio e luz para levar o oxigênio ao estado singlet, o qual é responsável, em última instância, pela peroxidação de lipídios nas membranas celulares. Lipídios e proteínas são atacados e oxidados o que resulta em perda da clorofila e de carotenóides e rompimento das membranas, o que faz com que as organelas das células se desintegrem. Os tecidos sofrem necrose e morte, causadas pela peroxidação dos lipídios (OLIVEIRA, 2001).

Apesar do flumioxazin ser utilizado como dessecante na cultura da soja, seu principal uso é como herbicida seletivo para aplicação em pós-emergência da cultura, na fase de dois 
a três trifólios, na dose de 50 g p.c.ha ${ }^{-1}$ (RODRIGUES; ALMEIDA, 2011). Entretanto, o herbicida possui também atividade no solo (OLIVEIRA et al., 1998; JAREMTCHUK, 2006) que proporciona controle residual das plantas daninhas, mas pode também afetar culturas subsequentes. Para o milho é recomendado o período de quatorze dias entre a aplicação do flumioxazin e a semeadura da cultura (RODRIGUES; ALMEIDA, 2011).

Desta forma, o presente trabalho foi desenvolvido com o objetivo de avaliar a eficácia do herbicida flumioxazin aplicado na dessecação pré-colheita da cultura da soja e seu efeito residual no controle de plantas daninhas e na seletividade para a cultura do milho safrinha.

\section{MATERIAL E MÉTODOS}

O trabalho foi desenvolvido no período de dezembro/2012 a setembro/2013, em área irrigada da Fazenda de Ensino e Pesquisa (FEP) da UNESP - FEIS, nas coordenadas de $20^{\circ} 20^{\prime} 34,0^{\prime}$ 'S de latitude, 51 24'01,7' WO de longitude, 360m de altitude e localizada no município de Selvíria, MS, enquadrada em região de cerrado, no Mato Grosso do Sul. O solo da área experimental é classificado como Latossolo Vermelho-Escuro textura argilosa, com $45 \%$ de argila.

A cultura da soja cultivar 'ST 660' convencional, da Soy Tech Seeds, foi semeada mecanicamente em 06/12/2012, no espaçamento de 0,50 m entre-linhas e lotação de 300 mil plantas por hectare. A semeadura foi realizada sob o sistema de plantio convencional e a emergência das plantas ocorreu em seis dias.

Os tratos culturais realizados na área experimental foram os normais exigidos pela cultura no que diz respeito às adubações e ao controle de pragas e doenças. Para o controle de doenças iniciais as sementes foram tratadas com o fungicida benomyl (50 g i.a. $100 \mathrm{~kg}^{-1}$ sementes). Antes da semeadura, realizou-se a inoculação das sementes, utilizando-se o produto Emerge PM à base de 20 gramas, diluídos em $600 \mathrm{ml}$ de água, para $80 \mathrm{~kg}$ de sementes. A adubação foi realizada concomitantemente à semeadura, utilizando-se a fórmula comercial 8-28-16 + 0,3\% de Zinco, com $250 \mathrm{~kg} \mathrm{ha}^{-1}$.

Foram realizadas duas aplicações de inseticida e fungicida, por época do florescimento e enchimento de grãos da cultura, para o controle de lagartas e percevejos e para prevenção de doenças. Os produtos utilizados foram o inseticida methamidophós na dose de $0,5 \mathrm{~L}_{\text {p.c.ha }}{ }^{-1}$ (300 g i.a. ha $\left.{ }^{-1}\right)$ e o fungicida Opera na dose de 0,5 L p.c. ha ${ }^{-1}(91,5 \mathrm{~g}$ i.a. $\left.\mathrm{ha}^{-1}\right)$. As aplicações foram realizadas com um pulverizador de barra tratorizado e volume de calda de $200 \mathrm{~L} \mathrm{ha}^{-1}$. As plantas daninhas que ocorreram durante o desenvolvimento do experimento foram controladas manualmente através de enxadas.

A cultura do milho cultivar 'AG 8088 Pro', foi semeada mecanicamente em 30/04/2013, quinze dias após a aplicação dos tratamentos na soja, no espaçamento de 1,00 $\mathrm{m}$ entre-linhas e 5,4 sementes por metro. A semeadura foi realizada sob o sistema de plantio direto sobre a palhada da soja e a emergência das plantas ocorreu em sete dias. A adubação

Cultura Agronômica, Ilha Solteira, v.26, n.4, p.683-693, 2017 
foi realizada concomitantemente à semeadura, utilizando-se a fórmula comercial 8-28-16 + 0,3\% de Zinco à base de $250 \mathrm{~kg} \cdot \mathrm{ha}^{-1}$, e adubação de cobertura, aos 25 dias após a emergência, com a fórmula 20-0-20 a $220 \mathrm{~kg} \mathrm{ha}^{-1}$. A aplicação de inseticida para o controle

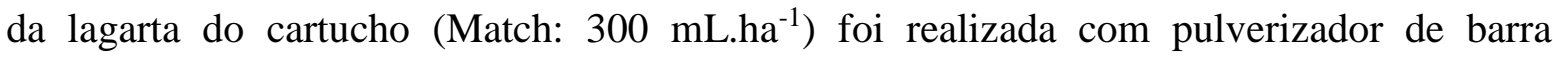
tratorizado e volume de calda de $200 \mathrm{~L} \mathrm{ha}^{-1}$.

O delineamento experimental foi o de blocos ao acaso, com doze tratamentos e quatro repetições. As parcelas foram dimensionadas com cinco metros de comprimento e quatro metros de largura, totalizando $20 \mathrm{~m}^{2}$. Foram semeadas oito linhas de soja por parcela e, na sequência após a colheita da soja, semeou-se quatro linhas de milho por parcela. A área total do experimento foi de $960 \mathrm{~m}^{2}$ (48 parcelas x $20 \mathrm{~m}^{2}$ ). Os tratamentos aplicados na dessecação da soja foram: flumioxazin $\left(100,120\right.$ e 150 g p.c. ha $\left.{ }^{-1}\right)+$ Assist $(0,5 \%$ v/v); flumioxazin + glyphosate $\left(100,120\right.$ e $150 \mathrm{~g}+1500 \mathrm{~mL}$ p.c. $\left.\mathrm{ha}^{-1}\right)+$ Assist $(0,5 \% \mathrm{v} / \mathrm{v})$; flumioxazin + paraquat $\left(120 \mathrm{~g}+2000 \mathrm{~mL}\right.$ p.c. $\left.\mathrm{ha}^{-1}\right)+$ Assist $(0,5 \% \mathrm{v} / \mathrm{v})$; flumioxazin + atrazin $\left(100\right.$ e $120 \mathrm{~g}+2500 \mathrm{~mL}$ p.c. $\left.\mathrm{ha}^{-1}\right)+$ Assist $(0,5 \% \mathrm{v} / \mathrm{v})$; atrazina $\left(4000 \mathrm{~mL}\right.$ p.c. ha $\left.{ }^{-1}\right) \mathrm{e}$ testemunha capinada e sem capina, conforme apresentados na Tabela 1.

Tabela 1. Tratamentos utilizados na dessecação para a colheita da cultura soja. Selvíria, MS (2013).

\begin{tabular}{lc}
\hline Tratamentos & Dose (p.c. ha $\left.{ }^{-1}\right)$ \\
\hline 01- Testemunha sem herbicida & -- \\
02- Testemunha capinada & -- \\
03- flumioxazin & $100 \mathrm{~g}$ \\
04- flumioxazin & $120 \mathrm{~g}$ \\
05- flumioxazin & $150 \mathrm{~g}$ \\
06- flumioxazin + glyphosate & $100 \mathrm{~g}+1,5 \mathrm{~L}$ \\
07- flumioxazin + glyphosate & $120 \mathrm{~g}+1,5 \mathrm{~L}$ \\
08- flumioxazin + glyphosate & $150 \mathrm{~g}+1,5 \mathrm{~L}$ \\
09- flumioxazin + paraquat & $120 \mathrm{~g}+2,0 \mathrm{~L}$ \\
10- atrazin & $4,0 \mathrm{~L}$ \\
11- flumioxazin + atrazin & $100 \mathrm{~g}+2,5 \mathrm{~L}$ \\
12- flumioxazin + atrazin & $120 \mathrm{~g}+2,5 \mathrm{~L}$ \\
\hline
\end{tabular}

Os produtos utilizados possuem as seguintes características: flumioxazin, nome comercial: Flumyzin 500, grupo químico: ciclohexenodicarboximida, concentração de ingrediente ativo: $500 \mathrm{~g} \mathrm{~kg}^{-1}$, formulação: pó molhável. Glyphosate, nome comercial: Roundup Transorb, grupo químico: derivado da glicina, concentração de ingrediente ativo: $648 \mathrm{~g} \mathrm{~L}^{-1}$, formulação: concentrado solúvel. Paraquat, nome comercial: Gramoxone 200, grupo químico: bipiridilos, concentração de ingrediente ativo: $200 \mathrm{~g} \mathrm{~L}^{-1}$, formulação: concentrado solúvel. Atrazin, nome comercial: Gesaprim 500, grupo químico: triazinas, concentração de ingrediente ativo: $500 \mathrm{~g} \mathrm{~L}^{-1}$, formulação: suspensão concentrada.

As aplicações dos herbicidas foram realizadas com um pulverizador costal com pressão constante $\left(\mathrm{CO}_{2}\right)$ de 40 libras/pol ${ }^{2}$, provido de tanque com capacidade de dois litros, 
e com barra equipada com quatro bicos do tipo leque, marca Teejet 110.03 (XR), espaçados de 0,5 metro. O volume de calda aplicado foi de $200 \mathrm{~L} \mathrm{ha}^{-1}$. As aplicações foram realizadas, no dia 15/04/2012, na pré-colheita da cultura da soja (aos 130 dias após a semeadura), quando a cultura atingiu a maturidade fisiológica com as vagens apresentando $80 \%$ de coloração marrom e as folhas com $70 \%$ de senescência natural, no estágio R7, conforme recomendado na maioria das pesquisas (DALTRO et al., 2010). As condições ambientais no momento das aplicações indicavam temperaturas de $27^{\circ} \mathrm{C}$, umidade relativa do ar de $60 \%$ e ventos praticamente nulos, conforme dados apresentados na Tabela 2.

Tabela 2. Resumo dos dados da aplicação. Selvíria, MS (2013).

\begin{tabular}{cccccccc}
\hline Data & $\mathrm{T}^{\circ} \mathrm{C}$ & URar & Ventos & $\begin{array}{c}\text { Volume } \\
\text { de calda }\end{array}$ & Cultura & $\begin{array}{c}\text { Época de } \\
\text { aplicação }\end{array}$ & $\begin{array}{c}\text { Estágio da } \\
\text { Cultura }\end{array}$ \\
\hline $15 / 04 / 12$ & $27^{\circ} \mathrm{C}$ & $60 \%$ & praticamente nulo & $200 \mathrm{~L} \mathrm{ha}^{-1}$ & soja & $130 \mathrm{DAS}$ & $\mathrm{R} 7$ \\
\hline
\end{tabular}

A avaliação de eficiência dos produtos foi realizada imediatamente antes da colheita da soja (aos 5 e 10 DAA = dias após a aplicação dos tratamentos dessecantes). As avaliações foram realizadas através de uma escala de observações visuais, na qual se comparou os tratamentos com a testemunha e estimou-se a porcentagem de dessecação ( 0 a $100 \%$ ) proporcionada pelos tratamentos. Considerou-se como eficiente os tratamentos com nível de desfolha maior do que $80 \%$.

A avaliação de produtividade foi realizada aos 10 DAA, coletando-se os grãos da área útil $\left(4 \mathrm{~m}^{2}\right.$ centrais). Após a colheita, as sementes de soja foram submetidas ao teste de germinação com intuito de se avaliar o efeito dos tratamentos sobre a qualidade das sementes.

Na cultura do milho, semeado após a colheita da soja, avaliou-se o efeito residual dos dessecantes aplicados na soja no controle das plantas daninhas, aos 60 dias após a semeadura (DAS), através de uma escala visual, onde $0 \%=$ nenhum controle e $100 \%=$ controle total das plantas daninhas, considerando-se como eficiente o controle $>80 \%$, conforme metodologia proposta por SBCPD (1995). A seletividade dos tratamentos às plantas da cultura do milho foi avaliada visualmente, considerando-se a biomassa e a coloração das plantas tratadas comparadas com as plantas testemunhas e atribuindo-se notas de $0 \%$ a $100 \%$, onde $0 \%=$ nenhum sintoma de fitotoxicidade e $100 \%=$ morte total das plantas. A avaliação de produtividade foi realizada aos 120 DAS (dias após a semeadura), coletando-se os grãos da área útil ( $4 \mathrm{~m}^{2}$ centrais $)$.

\section{RESULTADOS E DISCUSSÃO}

Os resultados de eficiência dos herbicidas aplicados na pré-colheita para a dessecação da cultura da soja e os dados de colheita estão apresentados na Tabela 1. Observa-se que os tratamentos proporcionaram níveis significativos de dessecação às plantas da cultura. Considerando a avaliação realizada aos 10 DAA, observa-se que todos os tratamentos proporcionaram níveis de dessecação superiores a $85 \%$. Estatisticamente destacaram-se os 
tratamentos flumioxazin $\left(120 \mathrm{~g}\right.$ e $150 \mathrm{~g}$ p.c. ha $\left.{ }^{-1}\right)$, flumioxazin + glyphosate $(100,120$ e 150 $\mathrm{g}+1500 \mathrm{~mL}$ p.c. $\left.\mathrm{ha}^{-1}\right)$, flumioxazin + paraquat $\left(120 \mathrm{~g}+2000 \mathrm{~mL}\right.$ p.c. ha $\left.{ }^{-1}\right)$ e flumioxazin + atrazin $\left(100\right.$ e $120 \mathrm{~g}+2500 \mathrm{~mL}$ p.c. $\left.\mathrm{ha}^{-1}\right)$, que proporcionaram níveis de dessecação superiores a 93\%. Os trabalhos de pesquisa sobre a dessecação da soja deram mais ênfase nos efeitos na qualidade das sementes (DALTRO et al., 2010).

Quanto aos dados de colheita (Tabela 3) observa-se que todos os tratamentos proporcionaram médias de germinação e produtividade estatisticamente iguais às testemunhas, mostrando que os produtos aplicados na maturação fisiológica da cultura não interferiram negativamente no rendimento e na qualidade germinativa das sementes da soja. Para o paraquat e o diquat, Daltro et al. (2010) observaram que o uso desses herbicidas como dessecantes não afetou o rendimento e a qualidade fisiológica das sementes de soja, já o glifosato afetou negativamente a qualidade das sementes.

Tabela 3. Eficácia dos tratamentos na dessecação da soja e dados de produtividade e germinação da cultura. Selvíria, MS (2013).

\begin{tabular}{|c|c|c|c|c|c|c|}
\hline \multirow{2}{*}{ Tratamentos } & \multirow{2}{*}{$\begin{array}{c}\text { Dose } \\
\text { p.c. } \text { ha }^{-1}\end{array}$} & \multicolumn{3}{|c|}{ \% Dessecação } & \multirow{2}{*}{$\begin{array}{c}\% \\
\text { Germ. }\end{array}$} & \multirow{2}{*}{$\begin{array}{c}\text { Produção } \\
\text { (kg/ha) }\end{array}$} \\
\hline & & $5 \mathrm{DAA}$ & $7 \mathrm{DAA}$ & $10 \mathrm{DAA}$ & & \\
\hline 01- Testemunha sem herbicida & -- & $69,5 \mathrm{e}$ & $72,5 \mathrm{~d}$ & $77,0 \mathrm{e}$ & 81,8 & 3405,8 \\
\hline 02- Testemunha capinada & -- & $70,0 \mathrm{e}$ & $72,5 \mathrm{~d}$ & $77,5 \mathrm{e}$ & 80,0 & 3362,5 \\
\hline 03-flumioxazin & $100 \mathrm{~g}$ & 75,0 de & $78,5 \mathrm{~cd}$ & $85,8 \mathrm{~d}$ & 84,8 & 3537,5 \\
\hline 04- flumioxazin & $120 \mathrm{~g}$ & $80,3 \mathrm{bcd}$ & $84,5 \mathrm{bc}$ & $93,0 \mathrm{bc}$ & 84,0 & 3475,0 \\
\hline 05-flumioxazin & $150 \mathrm{~g}$ & $84,8 \mathrm{bc}$ & $87,8 \mathrm{~b}$ & $96,5 \mathrm{ab}$ & 82,3 & 3500,0 \\
\hline 06- flumioxazin + glyphosate & $100 \mathrm{~g}+1,5 \mathrm{~L}$ & 77,5 cde & $83,5 \mathrm{bc}$ & $96,5 \mathrm{ab}$ & 81,8 & 3390,0 \\
\hline 07- flumioxazin + glyphosate & $120 \mathrm{~g}+1,5 \mathrm{~L}$ & $85,0 \mathrm{bc}$ & $87,5 \mathrm{~b}$ & $97,3 \mathrm{ab}$ & 80,5 & 3400,0 \\
\hline 08- flumioxazin + glyphosate & $150 \mathrm{~g}+1,5 \mathrm{~L}$ & $87,0 \mathrm{ab}$ & $89,5 \mathrm{ab}$ & $98,0 \mathrm{ab}$ & 79,5 & 3487,5 \\
\hline 09- flumioxazin + paraquat & $120 \mathrm{~g}+2,0 \mathrm{~L}$ & $94,5 \mathrm{a}$ & $96,0 \mathrm{a}$ & $99,0 \mathrm{a}$ & 78,5 & 3512,5 \\
\hline 10- atrazin & $4,0 \mathrm{~L}$ & $70,0 \mathrm{e}$ & $77,0 \mathrm{~cd}$ & $87,5 \mathrm{~cd}$ & 83,8 & 3562,5 \\
\hline 11- flumioxazin + atrazin & $100 \mathrm{~g}+2,5 \mathrm{~L}$ & $82,0 \mathrm{bcd}$ & $86,5 \mathrm{~b}$ & $94,0 \mathrm{ab}$ & 84,5 & 3325,0 \\
\hline \multirow[t]{5}{*}{ 12- flumioxazin + atrazin } & $120 \mathrm{~g}+2,5 \mathrm{~L}$ & $84,5 \mathrm{bc}$ & $88,0 \mathrm{~b}$ & $95,0 \mathrm{ab}$ & 82,3 & 3337,5 \\
\hline & Média Geral & 79,94 & 83,65 & 91,42 & 81,90 & 3441,3 \\
\hline & tratamentos) & $18,9 * *$ & $20,5 * *$ & $45,6 * *$ & $1,3^{\mathrm{ns}}$ & $0,3^{\underline{\mathrm{ns}}}$ \\
\hline & de Variação & $4,56 \%$ & $3,78 \%$ & $2,51 \%$ & $4,38 \%$ & $8,88 \%$ \\
\hline & DMS $(5 \%)$ & 9,04 & 7,85 & 5,68 & 8,91 & 758,68 \\
\hline
\end{tabular}

DAA = Dias Após a Aplicação dos tratamentos. Germ. = germinação

Obs.: médias com letras iguais nas colunas não diferem pelo teste de Tukey (5\%).

McNeal et al. (1973), Freitas (1984) e Kappes et al. (2009) também observaram melhorias na qualidade das sementes de soja dessecadas com diquat e paraquat. No presente trabalho, apesar das diferenças não terem sido significativas observou-se que os tratamentos com paraquat e glifosato tiveram médias de germinação das sementes sempre inferiores às médias do tratamento com o flumioxazin isolado. Andreoli e Ebeltoft (1979) afirmaram que uma das vantagens da aplicação de dessecantes é a aceleração na secagem dos grãos, o que

Cultura Agronômica, Ilha Solteira, v.26, n.4, p.683-693, 2017 
pode também ser atribuído ao presente trabalho já que os dados de germinação e produtividade não foram alterados.

Os resultados do efeito residual dos tratamentos no controle das plantas daninhas e na produtividade da cultura do milho safrinha, semeado após a colheita da soja, estão apresentados na Tabela 4.

Tabela 4. Eficácia dos tratamentos no controle das plantas daninhas na cultura do milho aos 60 dias após a semeadura (DAS) e dados de produtividade. Selvíria, MS (2013).

\begin{tabular}{|c|c|c|c|c|c|c|}
\hline \multirow{3}{*}{ Tratamentos } & \multirow{3}{*}{$\begin{array}{c}\text { Dose } \\
\text { p.c. } \text { ha }^{-1}\end{array}$} & \multicolumn{4}{|c|}{$\%$ de Controle aos 60 DAS } & \multirow[t]{3}{*}{$\begin{array}{l}\text { Produção } \\
\left(\mathrm{kg} \mathrm{ha}^{-1}\right)\end{array}$} \\
\hline & & $A$. & $I$. & $C$. & $P$. & \\
\hline & & & & is & maximum & \\
\hline \multicolumn{7}{|l|}{ 01- Testemunha sem herbicida } \\
\hline (controle natural) & -- & $55,0 \mathrm{c}$ & $82,5 \mathrm{c}$ & $80,0 \mathrm{f}$ & $65,0 \mathrm{~d}$ & $4211,7 \mathrm{~b}$ \\
\hline 02- Testemunha capinada & -- & $100,0 \mathrm{a}$ & $100,0 \mathrm{a}$ & $100,0 \mathrm{a}$ & $100,0 \mathrm{a}$ & $6457,9 \mathrm{a}$ \\
\hline 03-flumioxazin & $100 \mathrm{~g}$ & $92,5 \mathrm{c}$ & $93,5 \mathrm{ab}$ & 82,0 ef & $94,0 \mathrm{a}$ & $6630,6 \mathrm{a}$ \\
\hline 04- flumioxazin & $120 \mathrm{~g}$ & $96,5 \mathrm{ab}$ & $94,5 \mathrm{ab}$ & $91,0 \mathrm{bcd}$ & $95,0 \mathrm{a}$ & $6565,1 \mathrm{a}$ \\
\hline 05- flumioxazin & $150 \mathrm{~g}$ & $99,0 \mathrm{ab}$ & $95,0 \mathrm{ab}$ & $93,5 \mathrm{abc}$ & $96,5 \mathrm{a}$ & $6292,6 \mathrm{a}$ \\
\hline 06- flumioxazin + glyphosate & $100 \mathrm{~g}+1,5 \mathrm{~L}$ & $93,5 \mathrm{ab}$ & $93,0 \mathrm{ab}$ & 85,0 def & $94,5 \mathrm{a}$ & 5814,6 a \\
\hline 07- flumioxazin + glyphosate & $120 \mathrm{~g}+1,5 \mathrm{~L}$ & $97,0 \mathrm{ab}$ & $93,5 \mathrm{ab}$ & 87,5 cdef & $97,0 \mathrm{a}$ & $5559,9 \mathrm{ab}$ \\
\hline 08- flumioxazin + glyphosate & $150 \mathrm{~g}+1,5 \mathrm{~L}$ & $99,0 \mathrm{ab}$ & $94,0 \mathrm{ab}$ & 90,0 bcde & 97,0 a & $5487,0 \mathrm{ab}$ \\
\hline 09- flumioxazin + paraquat & $120 \mathrm{~g}+2,0 \mathrm{~L}$ & $98,0 \mathrm{ab}$ & $93,5 \mathrm{ab}$ & $90,5 \mathrm{bcd}$ & $90,0 \mathrm{ab}$ & $5782,8 \mathrm{a}$ \\
\hline 10- atrazin & $4,0 \mathrm{~L}$ & $97,0 \mathrm{ab}$ & $92,5 \mathrm{~b}$ & $92,5 \mathrm{abcd}$ & $77,5 \mathrm{c}$ & $5333,5 \mathrm{ab}$ \\
\hline 11- flumioxazin + atrazin & $100 \mathrm{~g}+2,5 \mathrm{~L}$ & $98,0 \mathrm{ab}$ & $97,0 \mathrm{ab}$ & $95,0 \mathrm{abc}$ & $83,5 \mathrm{bc}$ & $6485,3 \mathrm{a}$ \\
\hline \multirow[t]{5}{*}{ 12- flumioxazin + atrazin } & $120 \mathrm{~g}+2,5 \mathrm{~L}$ & $99,0 \mathrm{ab}$ & $97,5 \mathrm{ab}$ & $97,5 \mathrm{ab}$ & $95,3 \mathrm{a}$ & $5421,9 \mathrm{ab}$ \\
\hline & Média Geral & 93,71 & 93,88 & 90,38 & 90,44 & 5834,82 \\
\hline & tratamentos) & $72,01 * *$ & $7,93 * *$ & $12,50 * *$ & $25,23 * *$ & $6,76 * *$ \\
\hline & de Variação & $3,12 \%$ & $3,18 \%$ & $3,75 \%$ & $4,50 \%$ & $9,28 \%$ \\
\hline & DMS (5\%) & 7,25 & 7,42 & 8,41 & 10,10 & 1344,40 \\
\hline
\end{tabular}

A. tenella $=$ Alternanthera tenella $($ apaga-fogo $)=\mathrm{n}^{0} \mathrm{de} \mathrm{pls} \cdot \mathrm{m}^{-2}$ na testemunha sem herbicida $(60$ DAS $)=162,5$

I. nil $=$ Ipomoea nil $($ corda-de-viola $)=\mathrm{n}^{\mathrm{o}} \mathrm{de}$ pls. $\mathrm{m}^{-2}$ na testemunha sem herbicida $(60 \mathrm{DAS})=10,0$

C. benglalensis $=$ Commelina benglalensis (trapoeraba $)=\mathrm{n}^{\mathrm{o}}$ de pls. $\mathrm{m}^{-2}$ na testemunha sem herbicida $(60$ DAS $)=12,0$

P. maximum $=$ Panicum maximum $($ capim-colonião $)=\mathrm{n}-\mathrm{de}$ pls. $\mathrm{m}^{-2}$ na testemunha sem herbicida $(60 \mathrm{DAS})=12,5$

Obs.: médias com letras iguais nas colunas não diferem pelo teste de Tukey (5\%).

Observa-se pelos dados de controle das plantas daninhas que os tratamentos foram sempre superiores ao controle natural. Aos 60 DAS observou-se médias de controle natural, para a testemunha sem herbicidas, de 55,0\% para A. tenella; $82,5 \%$ para $I$. nil; $80,0 \%$ para C. benglalensis e $65,0 \%$ para $P$. maximum.

Considerando como eficiente o controle $\geq 80 \%$ (SBCPD, 1995), independente das diferenças estatísticas, observa-se que o tratamento flumioxazin isolado foi eficiente no controle das plantas daninhas, proporcionando, para a espécie A. tenella, níveis médios de controle de 92,5\%; 96,5\% e 99,0\% nas doses de 100; 120 e $150 \mathrm{~g} \mathrm{ha}^{-1}$, respectivamente. Para 
I. nil os níveis médios de controle foram de 93,5\%; 94,5\% e 95,0\% (doses de 100; 120 e $\left.150 \mathrm{~g} \mathrm{ha}^{-1}\right)$. Para $C$. benglalensis os níveis médios de controle foram de $82,0 \% ; 91,0 \%$ e 93,5\% (doses de 100; 120 e $150 \mathrm{~g} \mathrm{ha}^{-1}$ ). E, para $P$. maximum os níveis médios de controle foram de 94,0\%; 95,0\% e 96,5\% (doses de 100; 120 e $150 \mathrm{~g} \mathrm{ha}^{-1}$ ).

Para a espécie A. tenella, Jaremtchuk (2006) também observou controle residual eficaz da planta daninha com doses menores (50 e $\left.80 \mathrm{~g} \mathrm{ha}^{-1}\right)$ do que as utilizadas no presente trabalho. Com as mesmas doses o autor observou controle apenas moderado para a trapoeraba ( $C$. benghalensis) e corda-de-viola (I. grandifolia). Entretanto, Jaremtchuk (2006) considera que um controle de $60 \%$ já poderia ser considerado interessante por ser um benefício adicional da dessecação. Na dose de $120 \mathrm{~g}$ p.c. ha ${ }^{-1}$ do flumioxazin, Oliveira et al. (1998) observaram controle residual eficaz de $C$. benghalensis, semelhantes aos resultados obtidos no presente trabalho.

O tratamento flumioxazin + glyphosate foi eficiente no controle das plantas daninhas, proporcionando, para A. tenella, níveis médios de controle de 93,5\%; 97,0\% e 99,0\% nas doses de $100 ; 120$ e $150 \mathrm{~g}+1,5 \mathrm{~L} \mathrm{ha}^{-1}$, respectivamente. Para $I$. nil os níveis médios de controle foram de 93,0\%; 93,5\% e 94,0\% (doses de 100; 120 e $150 \mathrm{~g}+1,5 \mathrm{~L} \mathrm{ha}^{-1}$ ). Para $C$. benglalensis os níveis médios de controle foram de 85,0\%; 87,5\% e 90,0\% (doses de 100; 120 e $\left.150 \mathrm{~g}+1,5 \mathrm{~L} \mathrm{ha}^{-1}\right)$. E, para P. maximum os níveis médios de controle foram de 94,5\%; $97,0 \%$ e $97,0 \%$ (doses de 100; 120 e $150 \mathrm{~g}+1,5 \mathrm{~L} \mathrm{ha}^{-1}$ ). Para a espécie C. benglalensis e outras espécies, Adegas et al. (2000) também obtiveram controle residual satisfatório $(>85 \%)$ com o tratamento flumioxazin + glyphosate (na dose $120 \mathrm{~g}+1,5 \mathrm{~L} \mathrm{ha}^{-1}$ ).

$\mathrm{O}$ tratamento flumioxazin + paraquat $\left(120 \mathrm{~g}+2,0 \mathrm{~L} \mathrm{ha}^{-1}\right)$ foi eficiente no controle das plantas daninhas, proporcionando níveis médios de controle de 98,0\% para A. tenella, 93,5\% para I. nil, 90,5\% C. benglalensis e 90,0\% para P. maximum. Entretanto deve-se considerar que tanto o paraquat como o glyphosate não possuem atividade no solo (RODRIGUES; ALMEIDA, 2011) e que o efeito residual está relacionado apenas ao herbicida flumioxazin.

O tratamento atrazin $\left(4,0 \mathrm{~L} \mathrm{ha}^{-1}\right)$ isolado foi eficiente no controle das plantas daninhas, proporcionando níveis médios de controle de 97,0\% para A. tenella, 92,5\% para I. nil e 92,5\% C. benglalensis. Para a espécie $P$. maximum a baixa eficácia do tratamento $(77,5 \%)$ era esperada, já que o herbicida não é recomendado para essa espécie (LORENZI et al., 2006).

O tratamento flumioxazin + atrazin foi eficiente no controle das plantas daninhas, proporcionando, para A. tenella, níveis médios de controle de 98,0\% e 99,0\% nas doses de 100 e $120 \mathrm{~g}+2,5 \mathrm{~L} . \mathrm{ha}^{-1}$, respectivamente. Para $I$. nil, os níveis médios de controle foram de $97,0 \%$ e $97,5 \%$ (doses de 100 e $120 \mathrm{~g}+2,5 \mathrm{~L} \mathrm{ha}^{-1}$ ). Para C. benglalensis, os níveis médios de controle foram de $95,0 \%$ e $97,5 \%$ (doses de 100 e $120 \mathrm{~g}+2,5 \mathrm{~L} \mathrm{ha}^{-1}$ ). E, para $P$. maximum, os níveis médios de controle foram de $83,5 \%$ e $95,3 \%$ (doses de 100 e $120 \mathrm{~g}+2,5 \mathrm{~L} \mathrm{ha}^{-1}$ ).

Cultura Agronômica, Ilha Solteira, v.26, n.4, p.683-693, 2017 
Com relação à seletividade dos tratamentos, não foi observado nenhum sintoma de fitotoxicidade nas plantas da cultura do milho. Dan et al. (2009) também observaram total seletividade, para a cultura do milho safrinha, do herbicida flumioxazin aplicado na dessecação da cultura da soja.

Nos dados de produtividade, observa-se que a maior ocorrência de plantas daninhas no tratamento testemunha sem herbicida prejudicou o rendimento da cultura, conforme observado também por outros autores (CARVALHO; GALLI, 1993; VELINI et al., 1993; SILVA et al., 1993). Entre os tratamentos com herbicidas não ocorreu diferenças significativas nos dados de produtividade comparados ao da Testemunha Capinada.

\section{CONCLUSÃO}

O tratamento flumioxazin $\left(100,120\right.$ e 150 g p.c. ha $\left.{ }^{-1}\right)$ isolado foi eficiente na dessecação pré-colheita e seletivo na produtividade e germinação da cultura da soja cultivar ST 660, foi eficiente no controle residual de A. tenella, I. nil, C. benglalensis e P. maximum, e foi seletivo para a cultura subsequente de milho cultivar AG 8088 Pro.

Os tratamentos flumioxazin + glyphosate $\left(100,120\right.$ e $150 \mathrm{~g}+1,5 \mathrm{~L}$ p.c. $\left.\mathrm{ha}^{-1}\right)$, flumioxazin + paraquat $\left(120 \mathrm{~g}+2,0 \mathrm{~L}\right.$ p.c. $\left.\mathrm{ha}^{-1}\right)$ e flumioxazin + atrazin $(100 \mathrm{~g}$ e $120 \mathrm{~g}+2,5 \mathrm{~L}$ p.c. ha ${ }^{-1}$ ) também foram eficientes na dessecação pré-colheita e seletivo na produtividade $\mathrm{e}$ germinação da soja e foi eficiente no controle residual de A. tenella, I. nil, C. benglalensis e $P$. maximum, e foram seletivos para a cultura subsequente de milho.

\section{REFERÊNCIAS BIBLIOGRÁFICAS}

ADEGAS, F. S.; GAZZIERO, D. L. P.; BRIGHENTI, A. M.; VOLL, E. Eficiência de herbicidas utilizados no manejo para a implantação da cultura da soja em plantio direto. In: CONGRESSO BRASILEIRO DA CIÊNCIA DAS PLANTAS DANINHAS, 22., 2000, Foz do Iguaçu. Resumos... Londrina: SBCPD, 2000. p. 119.

ALMEIDA, F. S.; PINEDA-AGUILAR, A.; RODRIGUES, B. N. Resíduos de paraquat em grão de soja quando usado como dessecante da cultura. Planta Daninha, Viçosa, v. 9, n.12, p.85-91, 1991.

ANDREOLI, C.; EBELTOFT, D. C. Dessecantes no rendimento e na qualidade da semente de soja. Pesquisa Agropecuária Brasileira, Brasília, v. 14, n. 2, p.135-139, 1979.

CARVALHO, F. T.; GALLI, A. J. B. Nova formulação de alachlor na seletividade e no controle de plantas daninhas na cultura do milho. In: CONGRESSO BRASILEIRO DE HERBICIDAS E PLANTAS DANINHAS, 19. 1993, Londrina. Resumos... Londrina: SBHED, 1993. p. 131. 
DALTRO, E. M. F. ALBUQUERQUE, M. C. F.; FRANÇA NETO, J. B.; GUIMARÃES, S. C. Aplicação de dessecantes em pré-colheita: efeito na qualidade fisiológica de sementes de soja. Revista Brasileira de Sementes, Londrina, v. 32, n. 1, p.111-122, 2010.

DAN, H. A. DAN, L. G. M.; BARROSO, A. L. L.; OLIVEIRA NETO, A. M.; FINOTTI, T. R.; GUADANIN, E. C.; FELDKIRCHER, C.; GUERRA, N.; ALONSO, D. G.; OLIVEIRA JÚNIOR, R. S.; SANTOS, G. Efeito residual de herbicidas pré-emergentes utilizados na cultura da soja sobre o milho safrinha. In: SEMINÁRIO NACIONAL DE MILHO SAFRINHA, 10., 2009, Rio Verde. Trabalhos... Rio Verde: Associação Brasileira de Milho e Sorgo, 2009. p. 406-411.

DURIGAN, J. C.; CARVALHO, N. M. Aplicação, em pré-colheita, de dessecantes em duas cultivares de soja (Glycine max (L.) Merrill.): I - Efeitos imediatos sobre a germinação e produção de sementes. Planta Daninha, Viçosa, v. 3, n. 1, p.108-115, 1980.

EMBRAPA. Sistemas de Produção, 2. 2003. Disponível em: http://sistemasdeproducao.cnptia.embrapa.br/FontesHTML . Acesso em: 15 mai. 2017.

FREITAS, C. E. Aplicação em pré-colheita, de três dessecantes em plantas de soja (Glycine max (L.) Merrill), do cultivar IAC-8. Jaboticabal: Faculdade de Ciências Agrárias e Veterinárias, Universidade Estadual Paulista, 1984. 74 p. (Monografia)

INSTITUTO BRASILEIRO DE GEOGRAFIA E ESTATÍSTICA - IBGE. Estatística da Produção Agrícola. 2017. Disponível em: http://www.ibge.gov.br/home/estatística/indicadores/agropecuária/ispa/default.shtm. Acesso em: 15 mai. 2017.

JAREMTCHUK, C. C. Efeito residual e velocidade de dessecação de flumioxazin em sistemas de manejo antecedendo a semeadura da soja. 2006. 55 p. Dissertação (Mestrado em Agronomia) - Universidade Estadual de Maringá, Maringá, 2006.

KAPPES, C.; CARVAlHO, M. A. C.; YAMAShitA, O. M. Potencial fisiológico de sementes de soja dessecadas com diquat e paraquat. Scientia Agraria, Curitiba, v. 10, n. 1, p.1-6, 2009.

LACERDA, A. L. S.; LAZARINI, E.; SÁ, M. E.; VALÉRIO FILHO, W. V. Efeitos da dessecação de plantas de soja no potencial fisiológico e sanitário das sementes. Bragantia, Campinas, v. 64, n. 3, p.447-457, 2003.

LORENZI, H. Manual de Identificação e controle de plantas daninhas: plantio direto e convencional. 6. ed. Nova Odessa - SP: Plantarum, 2006. 339 p.

McNEAL, F. H.; HODGSON, J. M.; MCGUIRE, C. F.; BERG, M. A. Chemical desiccation experiments with hard red spring wheat (Triticum aestivum L.). Agronomy Journal, Madison, v. 65, n. 3, p.451-453, 1973.

Cultura Agronômica, Ilha Solteira, v.26, n.4, p.683-693, 2017 
OLIVEIRA, M. F.; SILVA, A. A.; NEVES, J. C. L. Influência do tamanho do agregado e do nível de umidade do solo na atividade do flumioxazin. Revista Ceres, Viçosa, v. 45, n. 257, p.81-87, 1998.

OLIVEIRA, R. S. Mecanismos de ação de herbicidas. In: OLIVEIRA, R. S.; CONSTANTIN, J. Plantas daninhas e seu manejo. Guaíba: Agropecuária, 2001. cap. 7, p. 232-235.

PELÚZIO, J. M. RAMO, L. N.; FIDELIS, R. R.; AFFÉRRI, F. S.; CASTRO NETO, M. D.; CORREIA, M. A. R. Influência da dessecação química e retardamento de colheita na qualidade fisiológica de sementes de soja no sul do estado do Tocantins. Bioscience Journal, Uberlândia, v. 24, n. 2, p.77-82, 2008.

RODRIGUES, B. N.; ALMEIDA, F. S. Guia de herbicidas. 6. ed. Londrina: Edição dos Autores, 2011. 697 p.

SOCIEDADE BRASILEIRA DA CIÊNCIA DAS PLANTAS DANINHAS - SBCPD. Procedimentos para instalação, avaliação e análise de experimentos com herbicidas. Londrina: SBCPD, 1995. 42 p.

SILVA, M. S. J; ASMUS, G. L.; CORREA, A. M. Estudo do herbicida nicosulfuron no controle de plantas daninhas na cultura do milho (Zea mays L.). In: CONGRESSO BRASILEIRO DE HERBICIDAS E ERVAS DANINHA, 19., 1993, Londrina - PR. Resumos... Londrina: SBHED, 1993. p. 148-149.

VELINI, E.; FREDERICO, L. A.; BICUDO, S. J.; ANTUNIASSI, U. R. Eficiência de herbicidas pré e pós emergentes iniciais recomendados para a cultura do milho, no controle de plantas daninhas e avaliação de efeitos dos mesmos sobre a produtividade da cultura. In: CONGRESSO BRASILEIRO DE HERBICIDAS E ERVAS DANINHAS, 19., 1993, Londrina - PR. Resumos... Londrina: SBHED, 1993. p. 141-142. 